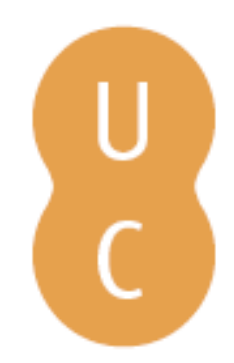

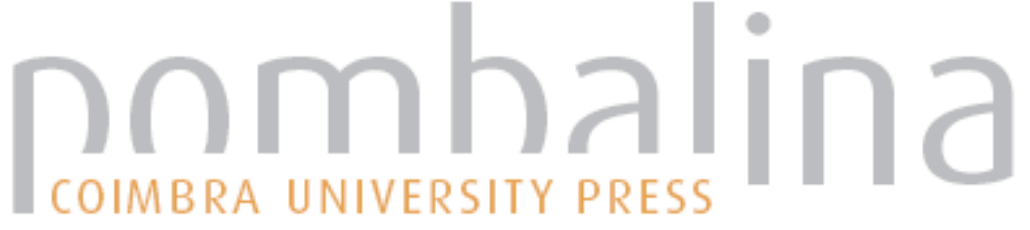

\section{Comentários ao artigo de David Ho}
Autor(es):
Paiva, Jorge
Publicado por: Imprensa da Universidade de Coimbra; Gradiva
URL
persistente:
URI:http://hdl.handle.net/10316.2/32698
DOI:
DOI:http://dx.doi.org/10.14195/978-989-26-0389-6_18

Accessed : $\quad$ 26-Apr-2023 02:24:53

A navegação consulta e descarregamento dos títulos inseridos nas Bibliotecas Digitais UC Digitalis, UC Pombalina e UC Impactum, pressupõem a aceitação plena e sem reservas dos Termos e Condições de Uso destas Bibliotecas Digitais, disponíveis em https://digitalis.uc.pt/pt-pt/termos.

Conforme exposto nos referidos Termos e Condições de Uso, o descarregamento de títulos de acesso restrito requer uma licença válida de autorização devendo o utilizador aceder ao(s) documento(s) a partir de um endereço de IP da instituição detentora da supramencionada licença.

Ao utilizador é apenas permitido o descarregamento para uso pessoal, pelo que o emprego do(s) título(s) descarregado(s) para outro fim, designadamente comercial, carece de autorização do respetivo autor ou editor da obra.

Na medida em que todas as obras da UC Digitalis se encontram protegidas pelo Código do Direito de Autor e Direitos Conexos e demais legislação aplicável, toda a cópia, parcial ou total, deste documento, nos casos em que é legalmente admitida, deverá conter ou fazer-se acompanhar por este aviso.

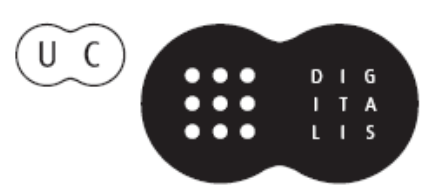


C I E N C I A I B E R T A

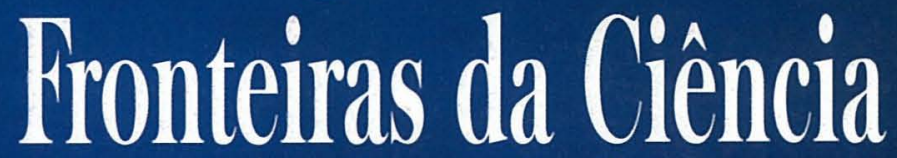

Desenvolvimentos Recentes - Desafios Futuros

RUI FAUSTO • CARLOS FIOLHAIS • JOÃO FILPE QUURRÓ

Coordenadores

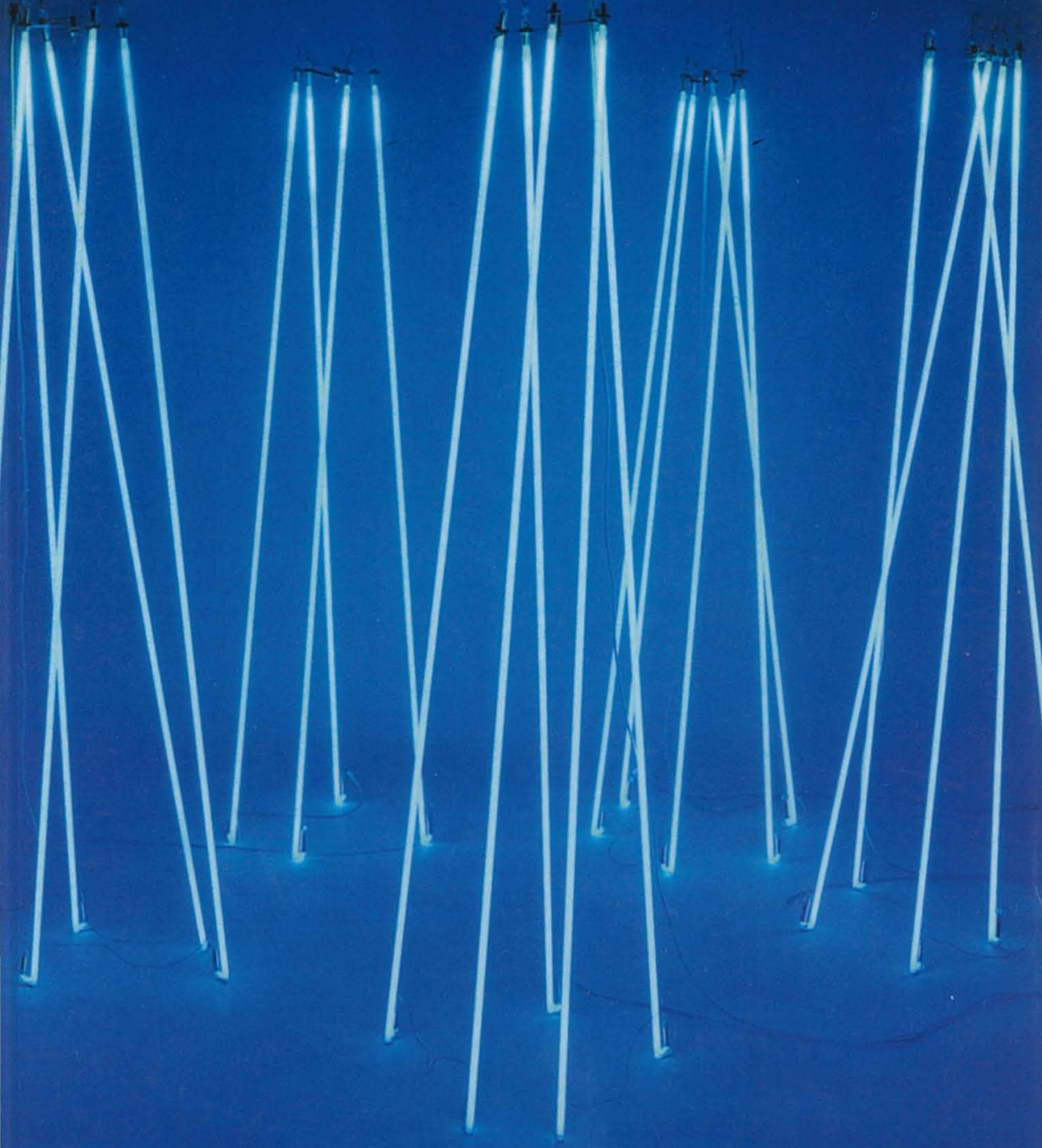

gradiva - Imprensa da Universidade de Coimbra 
(Página deixada propositadamente em branco) 


\section{RUI FAUSTO, CARLOS FIOLHAIS JOÃO FILIPE QUEIRÓ \\ Coordenadores}
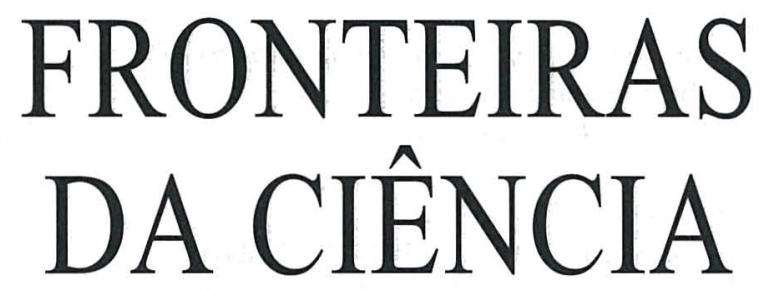

Desenvolvimentos Recentes Desafios Futuros 
(C) Gradiva - Publicações, L. da / Imprensa da Universidade de Coimbra, 2003 Coordenação editorial: Rui Fausto, Carlos Fiolhais e João Filipe Queiró Tradução: Jean Burrows, Vivien Burrows, Rui Fausto, Carlos Fiolhais e João Filipe Queiró

Revisão do texto: Isabel Pedrome

Capa: António Barros [Imprensa da Universidade. Coimbra], sobre imagem de «Águas Vivas», escultura de Silvestre Pestana, 2001

Foto: António Alves; Infografia: ESTÍMULUS [design]; Cortesia: Galeria Alvarez-Arte Contemporânea

Paginação: António Resende e Paula Isabel Jorge

Impressão e acabamento: G.C. - Gráfica de Coimbra, L. ${ }^{d a}$

Reservados os direitos para Portugal por:

Gradiva - Publicações, L. ${ }^{\text {da }}$ e Imprensa da Universidade de Coimbra

Gradiva - Publicações, L.da

Rua Almeida e Sousa, 21, r/c, esq.•1399-041 Lisboa

Telefs. $213974067 / 8 \cdot 213971357 \cdot 213953470$

Fax $213953471 \cdot$ Email: gradiva@ip.pt

URL: http://www.gradiva.pt

Imprensa da Universidade de Coimbra

Rua Antero de Quental, 195 • 3000-033 Coimbra

Telefs. 351239853110

Fax 3512398531 19・e-mail: fjrpress@ci.uc.pt

URL: http://www.imp.uc.pt

ISBN: 972-662-923-3

1." edição: Agosto de 2003

Depósito legal n. ${ }^{\circ} 199$ 463/2003 


\section{Comentários ao artigo de David Ho}

Embora o autor afirme no artigo que não é sua pretensão promover a Monsanto e que apenas trata de apresentar ciência, em todo o trabalho não só cita por diversas vezes a Monsanto, como também, quando refere outras empresas, não as identifica com os respectivos nomes, fazendo o mesmo para as revistas científicas, excepto quando os artigos são favoráveis às actividades da Monsanto (como o que cita da Nature). Nessa sua preocupação a considerar a biotecnologia amiga do ambiente! Por outro lado, no seu cuidado em promover aquela multinacional, congratula-se por, em Lisboa, se ter capacitado de que o termo Monsanto era um nome português, seguramente por ter sabido da existência em Lisboa do Parque de Monsanto. Não deve ter sabido que Monsanto é um toponímico relativamente frequente em Portugal, porque senão faria ainda mais propaganda desta multinacional.

Aliás, todo o artigo é uma apologia da biotecnologia. Todos sabemos que a agricultura tradicional não causa drásticas diminuições da biodiversidade, um facto de que a paisagem de bocage e os prados de lima, ainda presentes no Centro e Norte de Portugal, são um óptimo testemunho. Nesse processo de agricultura, os camponeses sempre utilizavam a técnica dos $3 \mathrm{R}$ (redução, reutilização e reciclagem), pois não só tinham apenas as parelhas de bois ou muares necessárias para os arados da área que tinham para cultivar (redução), como também utilizavam os restos de cereais e outras plantas para cama para o gado (reutilização), que depois serviam para estrumar os campos (reciclagem). 
Felizmente é uma prática não completamente extinta neste cantinho da Europa.

Com a designada revolução verde, iniciada há pouco mais de meio século, o arado de tracção animal foi substituído pelo tractor, deixando de haver reses para os serviços agrícolas. Assim, deixou de ser necessária a cama para o gado, não havendo, por isso, estrume. Consequentemente, não havendo reutilização nem reciclagem, passou a haver nas aldeias lixeiras que não existiam e os campos precisaram de adubos químicos. Então as multinacionais da agricultura incrementaram imediatamente a produção e utilização dos agroquímicos. Desta maneira abarrotou-se a biosfera com mais de 72000 produtos químicos, muitos deles nocivos e alguns letais. Infelizmente, não se elucidam convenientemente os agricultores sobre a utilização desses produtos altamente tóxicos. Assim, segundo dados da Organização Mundial de Saúde, morrem anualmente mais de 9000 pessoas e ocorrem mais de 500000 envenenamentos provocados por agroquímicos. David Ho, porém, só aponta os predicados positivos destes produtos, chegando ao ponto de afirmar que o herbicida glifotase, produzido pela Monsanto, não origina problemas de saúde!

Sabe-se como a revolução verde torna a população obesa pelo excesso de hormonas dadas ao gado e às plantas. Sabe-se ainda como as águas (fluviais, lacustres, oceânicas e friáticas) estão poluídas com o excesso de nitratos utilizados nos campos agrícolas (eutrofização) e com outros agroquímicos, impregnando as cadeias alimentares e acabando por se acumular no homem, que ocupa o topo das cadeias tróficas do globo. $\mathrm{O}$ caso do salmão que sobe os rios carregado de DDT é disso exemplo. Todos sabemos como os produtos alimentares estão abarrotados de agroquímicos.

Por outro lado, com a revolução verde a paisagem de bocage é destruída, pois as árvores que ladeiam os campos agrícolas prejudicam o trabalho com o tractor. Assim, houve um drástico derrube dendrológico, com a consequente diminuição da biodiversidade. O que aconteceu no Baixo Mondego é disso um bom exemplo. As árvores praticamente desapareceram e as cegonhas têm nidificar nos postes de alta tensão.

Actualmente estamos no início da designada revolução biotecnológica e, tal como no início da revolução verde, só se apontam os predicados positivos e nunca os malefícios.

Porém, já são conhecidos alguns danos, como o caso de uma bactéria modificada transgenicamente que produziu um composto que afectou a saúde de mais de 1500 pessoas e causou a morte de 27. Mas, tal como no início da revolução verde, agora com a revolução biotecnológica também se garante, tal como o autor faz, que se vai resolver o problema alimentar e da fome mundial. Sabemos que isso não é verdade. $\mathrm{Na}$ 
sociedade economicista em que vivemos, quando a produção é superior à necessidade do mercado é preferível destruir parte dela para manter os preços a inundar o mercado e vender ao desbarato. Nem sequer existe a preocupação de enviar esses excessos de produção para os países onde há fome.

É fundamental desmascararem-se não só os fundamentalistas do ambiente como também os fundamentalistas do lucro.

Não podemos deixar de assinalar que David Ho se preocupou essencialmente em apontar os benefícios aparentes da biotecnologia. Chega mesmo a considerar que, com a biotecnologia, há um aumento da biodiversidade, particularmente da genética, quando ele próprio se congratula com a homogeneidade genética dos cereais, em especial do milho (um dos produtos da Monsanto). Não diz ele que, de Lisboa a Coimbra, o milho que viu era todo geneticamente igual? 
 \\ A palavra "fronteiras" pode ser tomada em} diferentes sentidos. Pode referir-se aos limites, necessariamente provisórios, entre o conhecido e o desconhecido, ou aos limites entre o possivel e o impossivel, e, dentro do possivel, entre o desejável e 0 indesejável. Fronteiras podem também ser as delimitações, nem sempre nítidas, entre ciência e não-ciência, e dentro da ciência, entre as várias disciplinas. Quais são então as fronteiras da ciência?

Neste livro, a resposta a esta pergunta é dada, segundo as mais diferentes perspectivas, por um conjunto notável de personalidades, cientistas ou não, entre as quais se contam três Prémios Nobel.

Rui Fausto, Carlos fiolhais e JoÃo Fillipe Queiró são, respectivamente, professores de Química, Física e Matemática na Faculdade de Ciências e Tecnologia da Universidade de Coimbra. 